Check for updates

Cite this: RSC Adv., 2017, 7, 27331

\title{
Adsorption behavior of methylene blue onto waste- derived adsorbent and exhaust gases recycling
}

\author{
Song Cheng, ${ }^{\text {abcd }}$ Libo Zhang, ${ }^{\text {abcd }}$ Hongying Xia, (D) *abcd Jinhui Peng, ${ }^{\text {abcd }}$ \\ Jianhua Shu, ${ }^{\text {abcd }}$ Chunyang Li, ${ }^{\text {abcd }}$ Xin Jiang ${ }^{\text {abcd }}$ and Qi Zhang ${ }^{\text {abcd }}$
}

A waste-derived adsorbent was prepared from waste carbon, which was obtained from the production process of monosodium glutamate, by microwave heating under ultrasonic spray conditions for removing methylene blue (MB) from wastewater. The preparation process was performed at $840{ }^{\circ} \mathrm{C}$ for $17 \mathrm{~min}$ with an ultrasonic spray rate of $2 \mathrm{~mL} \mathrm{~min}^{-1}$ produced by ultrasonic spray equipment. Ultrasonic spray was successfully used for the preparation of an adsorbent from waste carbon for the first time. An adsorbent was also prepared under a steam atmosphere. The MB adsorption number of the adsorbent prepared under ultrasonic spray conditions increased by $15.27 \%$ in comparison to that prepared under a steam atmosphere under similar experimental conditions. The exhaust gases that were obtained during the preparation process of the adsorbent had a certain heating value, as the major components were carbon monoxide and hydrogen. The exhaust gases have promising utility as a heat source, which would significantly alter the commercial manufacturing process. The physicochemical properties of the adsorbent were investigated via $\mathrm{N}_{2}$ adsorption, TG/DTG, SEM, FTIR, XPS and zeta potential measurements. Analyses of the adsorption mechanism prove that $\mathrm{C}=\mathrm{O}$ bonds in the adsorbent play an important role in the adsorption process of $M B$, as proved by zeta potential measurements and XPS analysis. The above-mentioned analyses show that an adsorbent with good MB adsorption performance can be prepared from waste carbon under ultrasonic spray preparation conditions and fuel gas can be obtained at the same time, which achieves the comprehensive utilization of waste resources.

Received 5th February 2017

Accepted 26th April 2017

DOI: $10.1039 / c 7 r a 01482 a$

rsc.li/rsc-advances

\section{Introduction}

Dyes are coloring agents used by a variety of industries, including the textile, plastics, and paper and pulp industries, among others, to colorize their final products. A total of $30 \%$ of the world production of dyes may be lost during the dyeing process, and most dyes are toxic. ${ }^{1}$ The uncontrolled release of dye residues as industrial wastewater into water streams has led to a number of negative impacts, including a decrease in light penetration and carcinogenic and mutagenic changes to organisms. ${ }^{2}$ Dye wastewater can also cause allergy, dermatitis, and skin irritation and induce cancer and mutations in humans. ${ }^{3,4}$ Therefore, high contents of dyes in wastewater must be treated before discharge into the environment so as to minimize the threat to the environment and potential hazards. ${ }^{4}$ However, dyes are very difficult to biodegrade and remove from

\footnotetext{
${ }^{a}$ State Key Laboratory of Complex Nonferrous Metal Resources Clean Utilization, Kunming University of Science and Technology, Kunming, Yunnan 650093, China

${ }^{b}$ Yunnan Provincial Key Laboratory of Intensification Metallurgy, Kunming University of Science and Technology, Kunming, Yunnan 650093, China

'National Local Joint Laboratory of Engineering Application of Microwave Energy and Equipment Technology, Kunming, Yunnan 650093, China

${ }^{d}$ Faculty of Metallurgical and Energy Engineering, Kunming University of Science and Technology, Kunming, Yunnan 650093, China
}

dye wastewater owing to their high solubility in water and complex aromatic molecular structures. ${ }^{5}$ The provision of an effective method for controlling and treating dye wastewater has become urgent.

Many methods are used for the treatment of dye wastewater, including reverse osmosis, ${ }^{6}$ chemical oxidation, ${ }^{7}$ membrane filtration, ${ }^{8}$ ozonation, ${ }^{9}$ and biosorption. ${ }^{10}$ However, these methods are generally less effective in the treatment of dye wastewater or incur higher costs in the operating process. Among these methods, adsorption has attracted our attention owing to its many advantages such as higher efficiency, environment-friendliness and lower cost. ${ }^{11}$ The choice of an appropriate precursor plays an important role in the preparation of an adsorbent. In order to make adsorption an economical and environmentally friendly technology for wastewater treatment, an adsorbent is usually prepared from a variety of sustainable and cheaper precursors such as waste rubber tires, ${ }^{12}$ waste pulp solution, ${ }^{13}$ and waste plastics. ${ }^{14}$

Activated carbon is currently used in the monosodium glutamate industry in decolorization processes during refining. These processes generally produce large amounts of waste carbon with a low residual adsorption capacity. This waste carbon is not only a drain on resources, but can also cause harm to the environment. Therefore, processes that can use the waste 
carbon to prepare an adsorbent employed in processes for the treatment of dye wastewater would prove beneficial and achieve the comprehensive utilization of waste resources.

Currently, a variety of techniques for using waste carbon to prepare an adsorbent have been evaluated, including thermal, ${ }^{15}$ chemical, ${ }^{16}$ biological, ${ }^{17}$ and wet air oxidation, ${ }^{18}$ electrochemical processes, ${ }^{19}$ and ultrasonic ${ }^{20}$ and microwave heating. ${ }^{21,22}$ One of the most widely used methods is thermal treatment. However, electrical furnace heating has several disadvantages such as a uniform temperature distribution, high energy consumption and a slow rise in temperature. ${ }^{23,24}$ Recently, the issues involved in thermal treatment were addressed via a novel microwave heating process. Microwave heating has attracted attention as a promising method for treating waste carbon for the preparation of an adsorbent owing to its capability for molecular-level heating, rapid thermal reactions, precise temperature control, energy savings, selective heating, and lack of direct contact between the heating source and the materials. ${ }^{25,26}$ Steam, carbon dioxide and inert gases are generally used as activating agents to assist in the preparation of adsorbents from waste carbon, of which steam is the most widely used. Recently, ultrasonic spray techniques have been widely used in the synthesis process of various nanostructured materials with numerous advantages such as cost-effectiveness and a simple experimental setup. ${ }^{27-29}$ To date, a limited number of studies have employed ultrasonic spray as an activating agent to assist in the preparation of adsorbents from waste carbon. Unlike high-temperature steam, ultrasonic spray is produced at room temperature by ultrasonic spray equipment and can therefore reduce energy consumption. Furthermore, the adsorption performance of adsorbents prepared by ultrasonic spray is better than that of adsorbents prepared using steam.

However, there is a relative lack of research in the literature about the preparation of adsorbents from waste carbon combining the advantages of ultrasonic spray and microwave heating. In this work, waste carbon obtained from the production process of monosodium glutamate was used to prepare an adsorbent by microwave heating under ultrasonic spray conditions. For comparison with the adsorption performance of the adsorbent prepared under ultrasonic spray conditions, another adsorbent was prepared under a steam atmosphere under the same experimental conditions. During the preparation process, exhaust gases were inevitably produced via a series of chemical reactions and were collected for utilization owing to the resource utility of hydrogen and carbon monoxide. $\mathrm{MB}$ is a typical dye and was used to assess the mobility of organic dyes in dye wastewater treated with the waste-derived adsorbent. In addition, the equilibrium, kinetics, and thermodynamics of the adsorption process were studied in detail. Thermodynamic parameters such as $E_{\mathrm{a}}, \Delta S, \Delta H$, and $\Delta G$ were calculated to predict the adsorption behavior.

\section{Experimental}

\subsection{Materials and methods}

The detailed parameters of the waste carbon were as follows: an MB adsorption number of $39 \pm 3 \mathrm{mg} \mathrm{g}^{-1}$, a BET surface area of
$318.2 \mathrm{~m}^{2} \mathrm{~g}^{-1}$, and an electromagnetic constant of 1.241. The proximate analysis of the waste carbon is presented as follows: fixed carbon $73.9 \%$, ash $3.61 \%$ and volatile matter $22.49 \%$. The chemical composition of the waste carbon is represented in content percentages as follows: N 1.633\%, C 33.74\%, H 3.547\% and other elements $61.08 \%$. The waste carbon from the production process of monosodium glutamate was washed with deionized water. After being dried, the waste carbon was placed in a microwave furnace under an $\mathrm{N}_{2}$ atmosphere. When the temperature reached $840 \pm 5{ }^{\circ} \mathrm{C}$, the $\mathrm{N}_{2}$ flow was shut off and an ultrasonic spray at a rate of $2 \pm 0.1 \mathrm{~mL} \mathrm{~min}^{-1}$ produced by ultrasonic spray equipment was applied for $17 \mathrm{~min}$. When the holding time of 17 min was completed, the ultrasonic spray equipment was shut off and the $\mathrm{N}_{2}$ flow was restored. After being cooled to ambient temperature, the sample was taken out of the microwave furnace and stored for further characterization and adsorption experiments.

\subsection{Characterization}

$\mathrm{N}_{2}$ adsorption experiments on the waste carbon and adsorbent were conducted at $77 \mathrm{~K}$ using an automatic adsorption apparatus (Autosorb-1-C, USA) at a relative pressure $\left(P / P_{0}\right)$ ranging from $10^{-7}$ to 1 . The total pore volume was estimated as the equivalent liquid volume of the adsorbate $\left(\mathrm{N}_{2}\right)$ at a relative pressure of 0.99. The BET surface area of the samples was calculated by the Brunauer-Emmett-Teller (BET) equation. The pore size distribution was analyzed using the non-local density functional theory (NLDFT). The $t$-plot method was employed to calculate the micropore volume. The MB adsorption numbers of the waste carbon and adsorbent were calculated using the Standard Testing Methods of PR China (GB/T12496.8-1999). In order to observe the thermal decomposition behavior of the waste carbon, TG-DTG was carried out with a thermogravimetric analyzer (TherMax 500) in relation to temperature and time (heating rate: $10{ }^{\circ} \mathrm{C} \mathrm{min}^{-1}$, temperature range: $20-1000{ }^{\circ} \mathrm{C}$, nitrogen atmosphere). Scanning electron microscopy (SEM, Philips XL30ESEM-TMP) analysis was used to assess the surface morphology of samples. Fourier transform infrared spectroscopy (FTIR, Nicolet iS10, USA) was used to qualitatively determine the chemical functional groups present in the waste carbon and adsorbent. X-ray photoelectron spectroscopy (XPS) was performed with a PHI 5500 electron spectrometer (Physical Electronics, Inc., Chanhassen, MN, USA) using $200 \mathrm{~W} \mathrm{Mg}$ radiation. Zeta potential measurements were conducted using a ZetaPALS (zeta potential analyzer using phase analysis light scattering, Brookhaven Instruments Corp., USA) with a voltage of $110-240 \mathrm{~V}$ and a frequency of $50-60 \mathrm{~Hz}$.

\subsection{Adsorption isotherms}

MB was used as an adsorbate to assess the adsorption potential of the adsorbent prepared under ultrasonic spray conditions. Batch adsorption experiments were conducted in a series of 250 $\mathrm{mL}$ volumetric flasks. Samples of $0.1 \pm 0.001 \mathrm{~g}$ adsorbent and $100 \pm 1 \mathrm{~mL}$ MB solution of varying concentrations (100-300 mg $\mathrm{L}^{-1}$ ) were put into volumetric flasks. The volumetric flasks were shaken with a gas bath thermostatic oscillator at a shaking 
speed of $300 \pm 5 \mathrm{rpm}$ until equilibrium was reached at three different temperatures $\left(30,40\right.$ and $\left.50{ }^{\circ} \mathrm{C}\right)$. After equilibrium was reached, the residual $\mathrm{MB}$ concentration was calculated using a UV-vis spectrophotometer at $668 \mathrm{~nm}^{.1}$ The dose of MB adsorbed on the adsorbent, denoted as $q_{\mathrm{e}}\left(\mathrm{mg} \mathrm{g}^{-1}\right)$, was calculated using the following expression:

$$
q_{\mathrm{e}}=\left(C_{0}-C_{\mathrm{e}}\right) V / M
$$

where $C_{0}\left(\mathrm{mg} \mathrm{L}^{-1}\right)$ is the initial concentration of the MB solution and $C_{\mathrm{e}}\left(\mathrm{mg} \mathrm{L}^{-1}\right)$ is the equilibrium concentration of the $\mathrm{MB}$ solution. $V$ and $M$ are the volume of the solution (L) and the weight of the adsorbent $(\mathrm{g})$, respectively.

Three isotherm models were applied to fit the adsorption data, namely, Langmuir, Freundlich and Temkin. ${ }^{21}$ The three isotherm models and their parameters are presented in Table 1.

\subsection{Adsorption kinetics}

Adsorption kinetics studies were also carried out in volumetric flasks by similar methods to those described for adsorption isotherms. Samples were taken at preset time intervals and centrifuged at $300 \mathrm{rpm}$ for $5 \mathrm{~min}$. The supernatant fluid was used to calculate the residual concentration of MB via UV-vis spectroscopy. The amount of MB adsorbed at time $t$, denoted as $q_{t}\left(\mathrm{mg} \mathrm{g}^{-1}\right)$, was calculated by:

$$
q_{t}=\left(C_{0}-C_{t}\right) V / M
$$

where $C_{t}\left(\mathrm{mg} \mathrm{L}^{-1}\right)$ is the concentration of the liquid-phase $\mathrm{MB}$ solution at time $t(\mathrm{~min})$. The pseudo-first-order model, pseudosecond-order model, and intraparticle diffusion model were employed to analyze the kinetics data. ${ }^{22}$ The model equations and their parameters are listed in Table 2.

\section{Results and discussion}

\subsection{Thermal regeneration processes}

Thermogravimetric (TG) and derivative thermogravimetric (DTG) curves obtained for the waste carbon are shown in Fig. 1. The TG/DTG curves for the waste carbon suggest that three stages of weight loss occurred in the thermal decomposition process. The first stage can be associated with desorption of physically adsorbed water, free water and combined water in the range from 25 to around $200{ }^{\circ} \mathrm{C},{ }^{30}$ whereas the maximum rate of weight loss (27.5\%) took place in the second stage in the range from 200 to around $400{ }^{\circ} \mathrm{C}$ as a result of desorption of physisorbed compounds. ${ }^{31}$ The physisorbed compounds adsorbed by the waste carbon comprised glutamic acid and pigments. The third stage took place above $400{ }^{\circ} \mathrm{C}$ with no significant weight loss. This stage of mass loss was due to removal of the chemisorbed fraction as a result of cracking of the products formed by specific interactions between the surface groups of the carbon and the adsorbate, and breaking up of surface groups on the sample occurred simultaneously. ${ }^{32}$

\subsection{Pore structure and surface area analysis}

An adsorbent was also prepared under steam in order to compare its adsorption performance with that of an adsorbent prepared under ultrasonic spray conditions under identical conditions. Nitrogen adsorption isotherms of the waste carbon and adsorbents prepared under the two preparation conditions are shown in Fig. 2A (the term adsorbent-ultrasonic spray means that the adsorbent was prepared under ultrasonic spray conditions). The adsorption isotherm of adsorbent-ultrasonic spray was found to be higher than that of the adsorbent prepared under steam conditions, which indicates that there was a higher number of pores in adsorbent-ultrasonic spray. The pore size distribution is a vital indicator of an adsorbent that determines the fraction of the total pore volume that is accessible to molecules of a given size and shape. ${ }^{32}$ The average pore size of adsorbent-ultrasonic spray is $4.13 \mathrm{~nm}$, which indicates that adsorbent-ultrasonic spray is mesoporous because most of the pores and the sharpest peak in the pore distribution are in the range from 10 to $60 \AA$ (Fig. 2B). When adsorbent pore diameter is at least 1.7 times than that of the 186 adsorbate, adsorption can occur. ${ }^{33}$ Adsorbent-ultrasonic spray (4.13 nm) can easily adsorb MB molecule due to MB molecular size of $0.8 \mathrm{~nm}$.

The pore structure parameters of the waste carbon and adsorbents prepared under the two different preparation conditions are shown in Table 3 . The results demonstrate that the total pore volume, BET surface area, and micropore volume of the two adsorbents were significantly increased by microwave heating under the different preparation conditions, and the ultrasonic spray conditions gave rise to higher values. These results suggest that the pore structure of the adsorbents was more fully developed under ultrasonic spray conditions than under steam preparation conditions, which proves that the microwave-assisted ultrasonic spray preparation of an adsorbent from waste carbon is feasible.

Table 1 Adsorption isotherm models adopted in this work and their parameters

\begin{tabular}{lll}
\hline Isotherm & Equation & Parameters \\
\hline Langmuir isotherm & $\frac{1}{q_{\mathrm{e}}}=\frac{1}{k_{\mathrm{L}} Q_{0} C_{\mathrm{e}}}+\frac{1}{Q_{0}}$ & $\begin{array}{l}C_{\mathrm{e}} \text { is the equilibrium concentration }\left(\mathrm{mg} \mathrm{L}^{-1}\right) \\
Q_{\mathrm{o}}\left(\mathrm{mg} \mathrm{g}^{-1}\right) \text { is the adsorption constant related to the adsorption capacity } \\
k_{\mathrm{L}}\left(\mathrm{L} \mathrm{g}^{-1}\right) \text { is the adsorption constant related to the energy of adsorption } \\
k_{\mathrm{F}} \text { is the adsorption constant related to the adsorption capacity }\left(\mathrm{mg} \mathrm{g}^{-1}\right)\left(\mathrm{L} \mathrm{mg}^{-1}\right)^{1 / n} \\
n \text { is the adsorption constant corresponding to the adsorption intensity } \\
\text { Freundlich isotherm }\end{array}$ \\
$\begin{array}{ll}\ln \left(q_{\mathrm{e}}\right)=\ln \left(k_{\mathrm{F}}\right)+\frac{1}{n} \ln \left(C_{\mathrm{e}}\right) \\
\text { Temkin isotherm }\end{array}$ & $q_{\mathrm{e}}=A+B \ln \left(C_{\mathrm{e}}\right)$ & are constants
\end{tabular}


Table 2 Adsorption kinetics models adopted in this work and their parameters

\begin{tabular}{lll}
\hline Kinetics model & Equation & Parameters \\
\hline Pseudo-first-order & $\ln \left(q_{\mathrm{e}}-q_{t}\right)=\ln q_{\mathrm{e}}-k_{1} t$ & $\begin{array}{l}\left.q_{\mathrm{e}} \text { is the uptake of methylene blue at equilibrium (mg } \mathrm{g}^{-1}\right) \\
k_{1}\left(\mathrm{~min}^{-1}\right) \text { is the adsorption rate constant } \\
k_{2}\left(\mathrm{~g} \mathrm{mg}^{-1} \mathrm{~min}^{-1}\right) \text { is the rate constant of the second-order equation }\end{array}$ \\
Pseudo-second-order & $\frac{t}{q_{\mathrm{e}}}=\frac{1}{k_{2} q_{\mathrm{e}}^{2}}+\frac{t}{q_{\mathrm{e}}}$ & $\begin{array}{l}k_{3}\left(\mathrm{mg} \mathrm{g}^{-1} \mathrm{~min}^{-1 / 2}\right) \text { is the intraparticle diffusion rate constant } \\
\text { Intraparticle diffusion }\end{array}$ \\
$q_{t}=k_{3} \sqrt{t}+C$ & is a constant
\end{tabular}

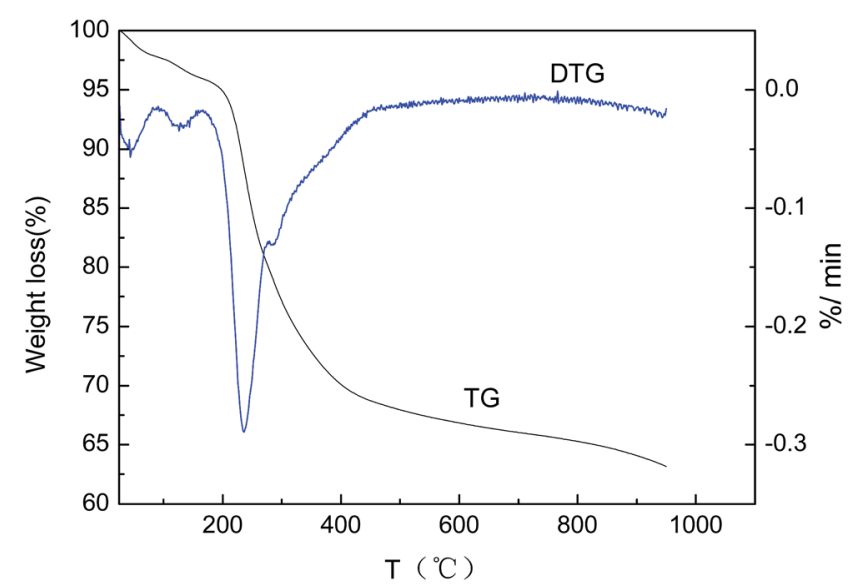

Fig. 1 TG/DTG curves for waste carbon.

\subsection{SEM analysis}

The microstructures of the waste carbon and adsorbents prepared under the two different preparation conditions are shown in Fig. 3. The microstructure of the waste carbon as observed by SEM is shown in Fig. 3A, whereas the microstructures of the adsorbents prepared under steam and ultrasonic spray preparation conditions are shown in Fig. 3B and C, respectively. The surface of the waste carbon was covered by impurities and the pore structure could not be clearly visualized (Fig. 3A). As shown in Fig. 3B, there were still some impurities on the surface of the adsorbent. The impurities on the surface of the adsorbent were removed and a clear pore structure is visible in Fig. 3C, which suggests that the adsorbent has a large surface area and pore volume.

\subsection{FTIR analysis}

FTIR spectra recorded for samples of the waste carbon and adsorbent-ultrasonic spray are shown in Fig. 4. As shown in Fig. 4, there are minimal differences in the general spectral shape between the waste carbon and adsorbent-ultrasonic spray. The characteristic absorption peaks of the waste carbon and adsorbent-ultrasonic spray at 3417 and $3431 \mathrm{~cm}^{-1}$ can be assigned to the $\mathrm{O}-\mathrm{H}$ stretching vibration mode of hydroxyl functional groups. ${ }^{34}$ The bands observed at 2922 and $2924 \mathrm{~cm}^{-1}$ suggest the presence of $\mathrm{C}-\mathrm{H}$ stretching vibrations. ${ }^{35}$ The band due to $\mathrm{C}=\mathrm{O}$ stretching vibrations is in the region of 1618 $\mathrm{cm}^{-1}{ }^{36}$ The band at $1119 \mathrm{~cm}^{-1}$ (C-OH vibrations) suggests the presence of many oxygen-containing functional groups. Some

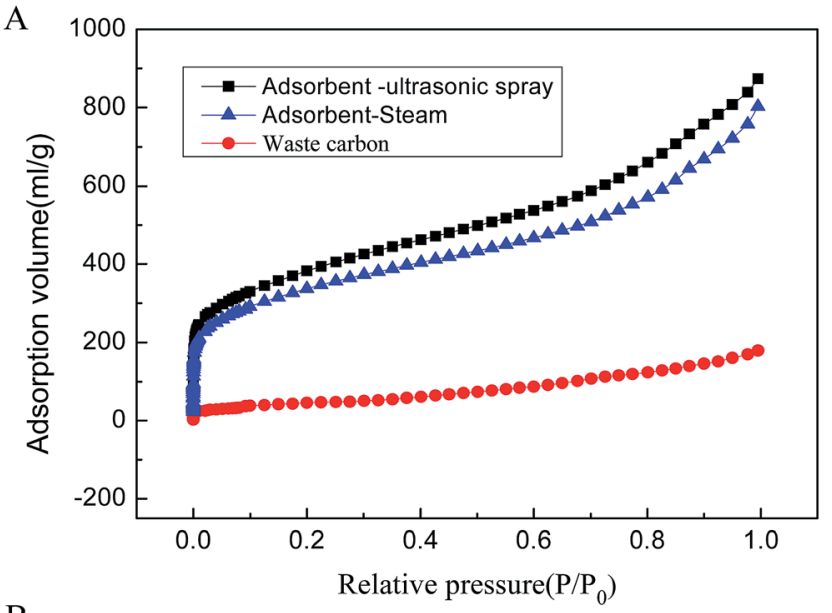

B

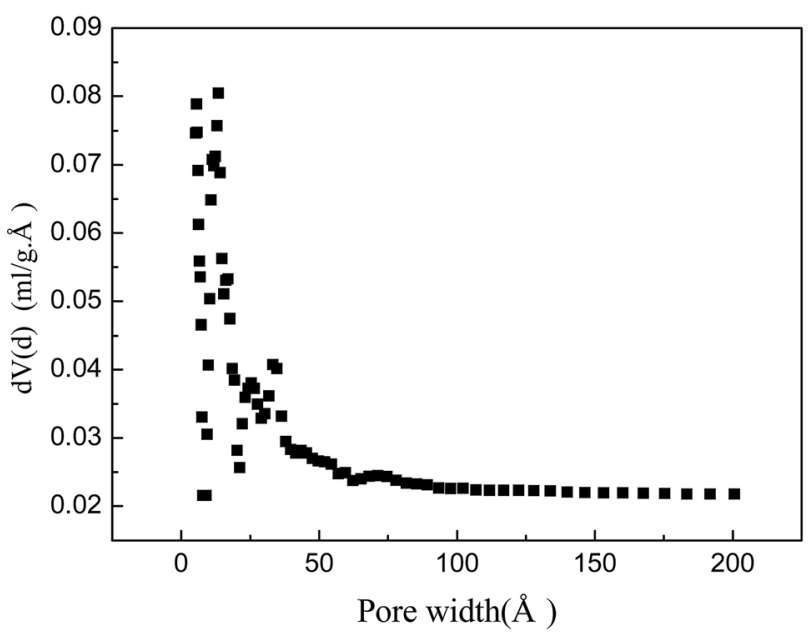

Fig. 2 (A) Nitrogen adsorption isotherms of the waste carbon and adsorbents prepared under the two different preparation conditions. (B) Pore size distribution of adsorbent-ultrasonic spray.

weak bands are also visible in the range of $600-900 \mathrm{~cm}^{-1}$ and are likely to be associated with the out-of-plane bending mode of $\mathrm{C}-\mathrm{H}$ or $\mathrm{O}-\mathrm{H}$ groups. ${ }^{37}$ On comparing the FTIR spectrum of the waste carbon with that of adsorbent-ultrasonic spray, there are several differences in the bands, such as that between 3417 and $3431 \mathrm{~cm}^{-1}$. These differences may be attributed to the decomposition of organic material in the waste carbon, which resulted in a change in peak value. The weak bands in the range of $600-900 \mathrm{~cm}^{-1}$ for adsorbent-ultrasonic spray disappeared, which suggests that hydrogen was removed during the 
Table 3 Pore structure parameters of waste carbon and adsorbents prepared in two different preparation conditions

\begin{tabular}{|c|c|c|c|c|c|c|}
\hline Subject & $S_{\text {BET }}\left(\mathrm{m}^{2} \mathrm{~g}^{-1}\right)$ & $V_{\text {tot }}\left(\mathrm{mL} \mathrm{g}^{-1}\right)$ & $\mathrm{Da}(\mathrm{nm})$ & $V_{\text {mic }}\left(\mathrm{mL} \mathrm{g}^{-1}\right)$ & $V_{\text {mic }} / V_{\text {tot }}(\%)$ & $\begin{array}{l}\text { MB adsorption } \\
\text { number }\left(\mathrm{mg} \mathrm{g}^{-1}\right)\end{array}$ \\
\hline Waste carbon & 318 & 0.517 & 9.32 & 0.07 & 13.54 & 39 \\
\hline Adsorbent-steam & 1151 & 1.22 & 4.33 & 0.31 & 25.40 & 166.5 \\
\hline
\end{tabular}

microwave heating process. ${ }^{38}$ This result is consistent with that of the elemental analysis (in comparison with the $\mathrm{H}$ content of spent activated carbon of $3.547 \%$, the $\mathrm{H}$ content of adsorbentultrasonic spray is $1.586 \%)$.

\subsection{XPS analyses}

The XPS technique was employed to determine the composition and surface groups of the waste carbon and adsorbentultrasonic spray. Deconvolution of the C 1s signals enabled the identification of the chemical states and environment of the carbon atoms (Fig. 5A for waste carbon and Fig. 5B for adsorbent-ultrasonic spray). As shown in Fig. $5 \mathrm{~A}$ and $\mathrm{B}$, the primary element is $\mathrm{C}$, with variable peak intensities at the binding energy of this element of $284.6 \mathrm{eV}$ (C 1s) ${ }^{39}$ which can be deconvolved into the peaks of three surface groups at 284.8 (CC), $285.7(\mathrm{C}-\mathrm{OH})$ and $289.7 \mathrm{eV}(\mathrm{C}=\mathrm{O})$. When compared with Fig. $5 \mathrm{~A}$ and $\mathrm{B}$, the contents of $\mathrm{C}-\mathrm{O}$ and $\mathrm{C}=\mathrm{O}$ in activated carbon increased from $27.68 \%$ to $30.63 \%$ and from $3.80 \%$ to $16.19 \%$, respectively. Both these surface groups contributed to the adsorption of $\mathrm{MB}$, which indicates that the method of microwave-assisted ultrasonic spray preparation of an adsorbent is feasible.

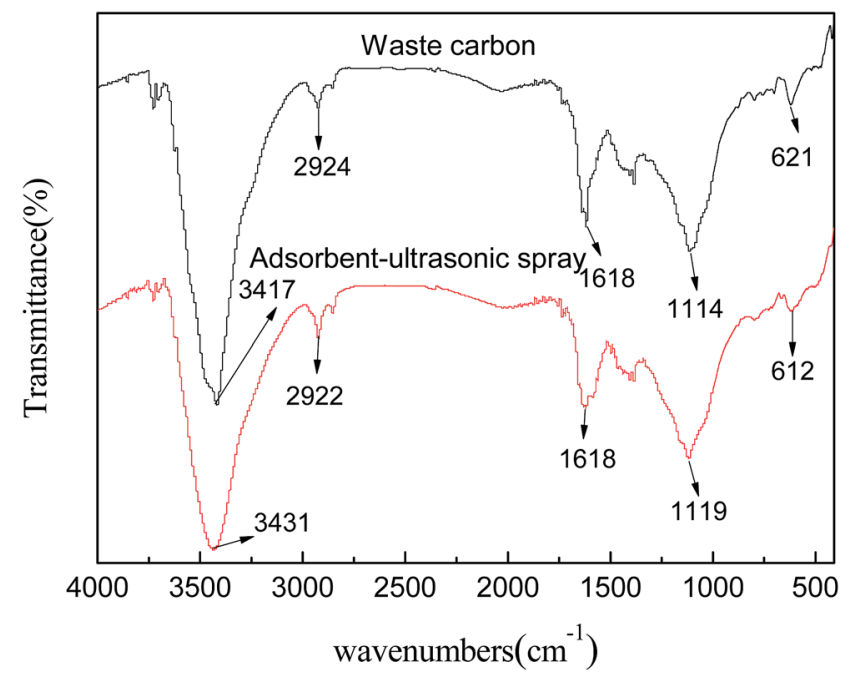

Fig. 4 FTIR spectra recorded for waste carbon and adsorbent-ultrasonic spray.

\subsection{Zeta potential measurements}

Adsorbents are usually considered to be amphoteric solids owing to the presence of a variety of surface functional groups. ${ }^{40}$
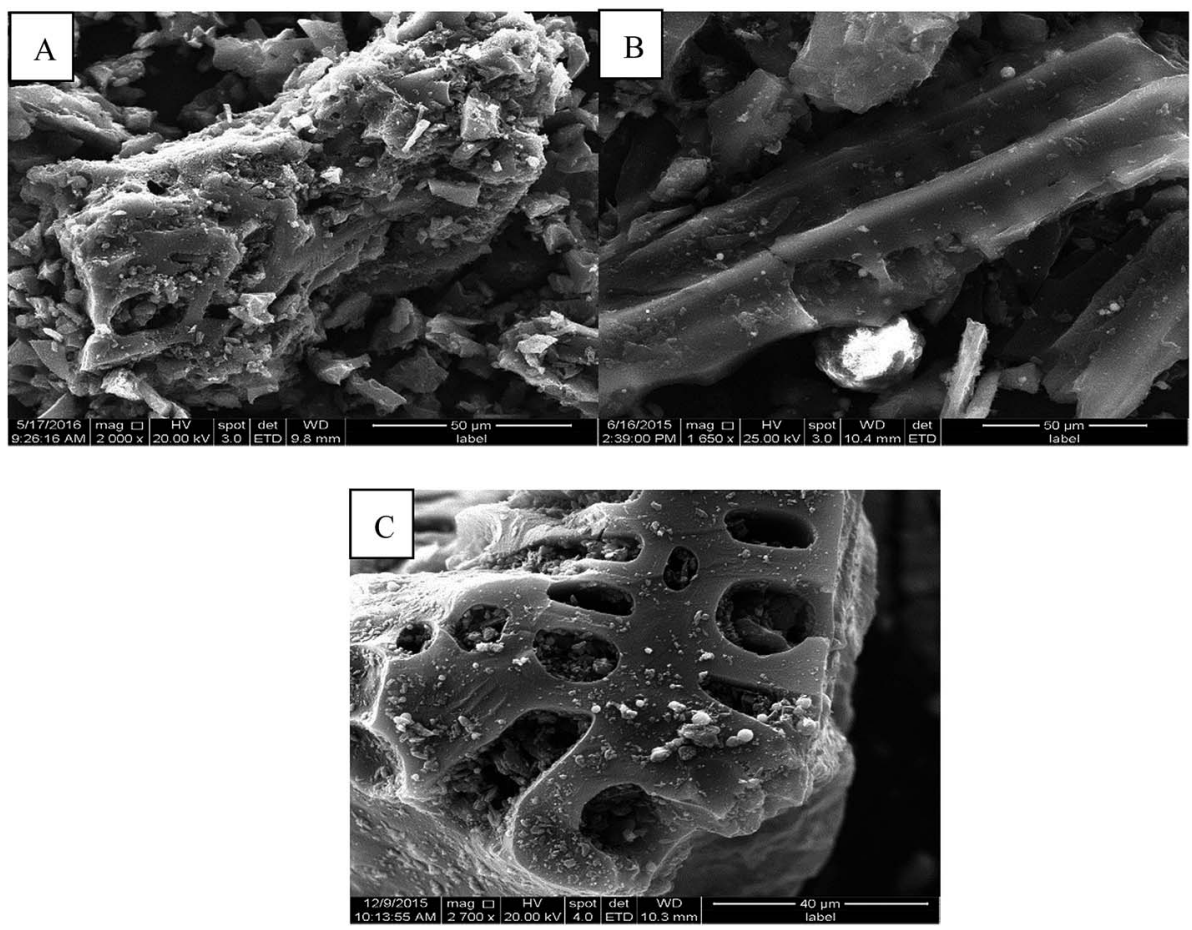

Fig. 3 SEM images of the waste carbon (a), adsorbents prepared under the steam (b) and ultrasonic spray (c) conditions. 

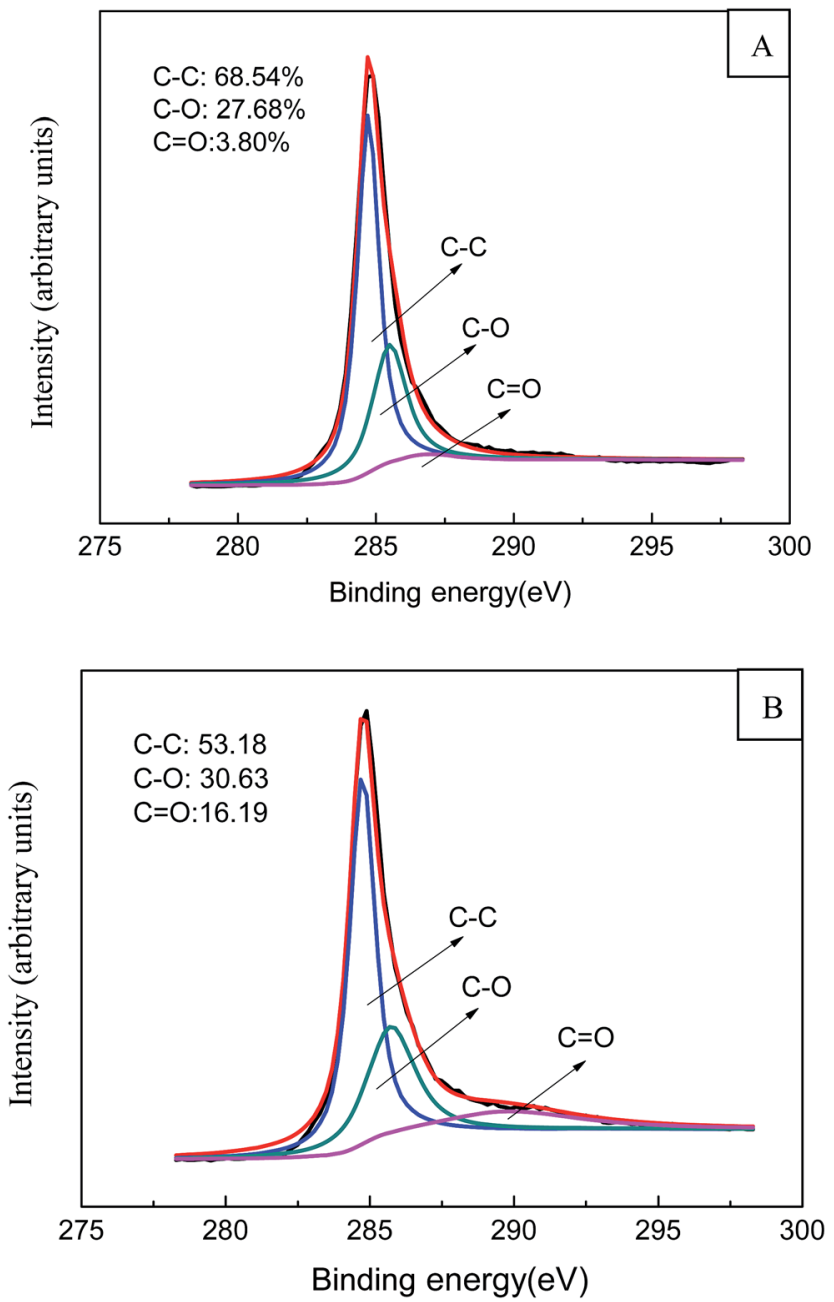

Fig. 5 C 1s XPS spectra of samples of waste carbon (A) and adsorbentultrasonic spray (B).

Therefore, the isoelectric point (IEP) of adsorbent-ultrasonic spray can be determined by measuring the $\mathrm{pH}$ value at which the zeta potential is zero. The IEP is used to qualitatively assess the polarity of the surface charge of an adsorbent. ${ }^{41} \mathrm{At}$ a $\mathrm{pH}$ of less than the IEP, an adsorbent has a positive surface charge and can act as an anion exchanger, whereas at a $\mathrm{pH}$ of greater than the IEP the surface charge of an adsorbent is negative, which is beneficial for the adsorption of cations. ${ }^{42}$ The IEP values of adsorbent-ultrasonic spray at different $\mathrm{pH}$ values are presented in Fig. 6. The IEP of adsorbent-ultrasonic spray was found to be 7.2 (Fig. 6). The $\mathrm{pH}$ value of adsorbent-ultrasonic spray during the course of the adsorption experiment was about 6-7. Therefore, adsorbent-ultrasonic spray had a negative surface charge and would adsorb MB by electrostatic attraction because MB is a cationic dye.

\subsection{Recycling of exhaust gases}

Research into the gaseous by-products generated during the preparation process of adsorbents is seldom reported in the literature. Owing to their importance, the gases generated

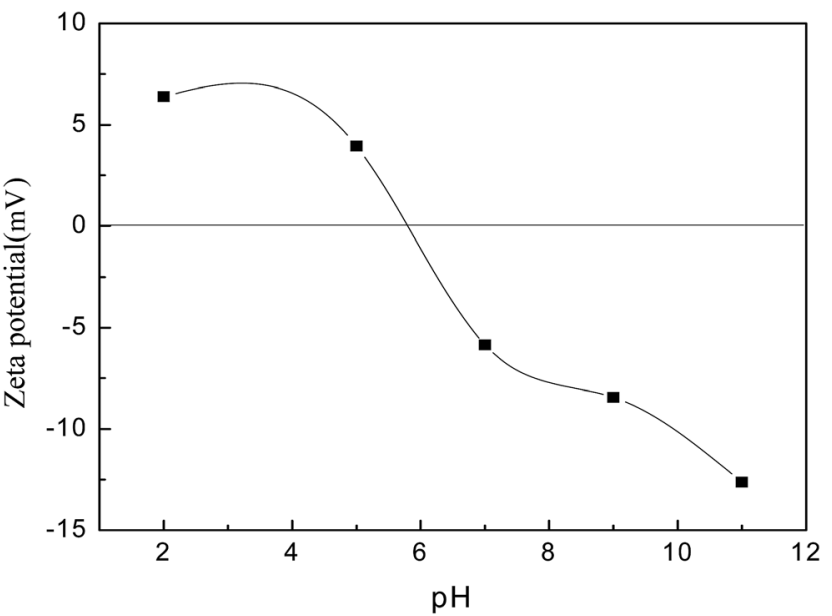

Fig. 6 Zeta potential of samples of adsorbent-ultrasonic spray at different $\mathrm{pH}$ values.

during the preparation process were collected. The gas composition of the exhaust gases is represented in relative content percentages as follows: $\mathrm{CO} 48.99 \%, \mathrm{H}_{2} 39.62 \%, \mathrm{CO}_{2}$ $7.85 \%, \mathrm{CH}_{4} 3.29 \%, \mathrm{C}_{2} \mathrm{H}_{4} 0.1 \%, \mathrm{C}_{2} \mathrm{H}_{2} 0.15 \%$. The contents of $\mathrm{CO}$ and $\mathrm{H}_{2}$ were higher than the contents of other gases. Therefore, the exhaust gases can be used as a gaseous fuel. Analyses of the gaseous products showed that they were mainly composed of $\mathrm{CO}, \mathrm{H}_{2}, \mathrm{CO}_{2}$, and $\mathrm{CH}_{4}$, and $\mathrm{CO}$ and $\mathrm{H}_{2}$ were the main components. The high proportions of $\mathrm{CO}$ and $\mathrm{H}_{2}$ can be attributed to the set of gasification reactions shown below.

$$
\begin{gathered}
\mathrm{C}+\mathrm{H}_{2} \mathrm{O} \rightarrow \mathrm{CO}+\mathrm{H}_{2} \\
\text { Organic matter } \rightarrow \mathrm{CO}_{2}+\mathrm{H}_{2} \mathrm{O} \\
\mathrm{C}+\mathrm{CO}_{2} \rightarrow 2 \mathrm{CO} \\
\left(-\mathrm{CH}_{2}-\right)+\mathrm{H}_{2} \mathrm{O} \rightarrow \mathrm{CO}+\mathrm{H}_{2} \\
\mathrm{CO}+3 \mathrm{H}_{2} \rightarrow \mathrm{CH}_{4}+\mathrm{H}_{2} \mathrm{O}
\end{gathered}
$$

Reaction (3) was the main reaction that contributed to the gas rich in $\mathrm{CO}$ and $\mathrm{H}_{2}$. The reactions are endothermic and thus require high energy inputs to promote the reaction. The heating values of the exhaust gases were determined on the basis of the composition of the gases, in particular, $\mathrm{CO}$ and $\mathrm{H}_{2}$. These gases could be collected for use as a gaseous fuel. In addition, the mixture of $\mathrm{CO}$ and $\mathrm{H}_{2}$ commonly known as syngas could be utilized for conversion into a variety of other useful fuels and chemicals via subsequent chemical conversions.

\subsection{Adsorption isotherm studies}

The adsorption isotherms were employed to analyze the adsorption mechanisms and determine how adsorbate molecules were distributed on the adsorbent. In this work, the results of fitting to the three isotherm equations are presented in Table 4. As Table 4 shows, the $R^{2}$ value for the Langmuir isotherm was larger than those for the other two isotherms, 
which indicates that the Langmuir isotherm provided the best fit to the experimental data, whereas the Freundlich and Temkin isotherms did not closely match the experimental data. The findings also show that $\mathrm{MB}$ on the surface of adsorbentultrasonic spray tended to exhibit monolayer adsorption. The amount of MB that was adsorbed increased with an increase in temperature, which suggests that the adsorption process was endothermic in nature (Table 4). A similar trend was reported by Theydan and Ahmed ${ }^{\mathbf{4}}$ for the adsorption of MB on biomassbased activated carbon. This can be explained by the fact that the surface activity and kinetic energy gradually increased with an increase in temperature, which led to the interaction forces between the solute and adsorbent becoming stronger than those between the solute and solvent. ${ }^{43}$ The maximum monolayer adsorption capacities of various adsorbents for $\mathrm{MB}$ are listed in Table 5. The $Q_{0}$ value of adsorbent-ultrasonic spray is the largest of those reported, ${ }^{44-48}$ which suggests that adsorbentultrasonic spray has great potential for applications in the removal of $\mathrm{MB}$. Thus, it is noteworthy that considerable changes in the surface properties were achieved, which should be attributed to the distinct mechanism of microwave heating. ${ }^{\mathbf{4 9}}$ Langmuir isotherms for the adsorption of MB onto adsorbentultrasonic spray at different temperatures are shown in Fig. 7A. Fig. 7B and C show photographs of MB solution Fig. 7B and the solution treated using adsorbent-ultrasonic spray Fig. 7C. As Fig. 7C shows, MB dye almost completely disappeared owing to remarkable adsorption by adsorbentultrasonic spray. The result shows that adsorbent-ultrasonic spray is an effective adsorbent for adsorbing MB.

\subsection{Adsorption kinetics studies}

Adsorption kinetics studies can provide important parameters of the adsorption process in the treatment of aqueous effluents. In order to study the mechanism of the adsorption of $\mathrm{MB}$, pseudo-first-order and pseudo-second-order models were employed to examine the adsorption process, whereas the diffusion mechanisms were examined using the intraparticle diffusion model. The model parameters were calculated using the three models listed in Table 6. The accurateness between the experimental values and the results calculated using the models was evaluated in terms of the value of $R^{2}$ (correlation coefficient). A relatively high $R^{2}$ value indicates that the model is more applicable for describing the adsorption of $\mathrm{MB}$ onto the

Table 4 Adsorption isotherm parameters

\begin{tabular}{llccc}
\hline & & \multicolumn{3}{c}{ Temperature $(\mathrm{K})$} \\
\cline { 3 - 5 } Isotherm & Parameter & 303 & 313 & 323 \\
\hline \multirow{2}{*}{ Langmuir } & $Q_{0}\left(\mathrm{mg} \mathrm{g}^{-1}\right)$ & 261.78 & 276.24 & 289.85 \\
& $k_{\mathrm{L}}\left(\mathrm{L} \mathrm{mg}^{-1}\right)$ & 2.0761 & 2.1047 & 2.2258 \\
& $R^{2}$ & 0.99 & 0.99 & 0.99 \\
Freundlich & $1 / n$ & 0.1722 & 0.1990 & 0.2441 \\
& $k_{\mathrm{F}}\left(\left(\mathrm{mg} \mathrm{g}^{-1}\right)\left(\mathrm{L} \mathrm{mg}^{-1}\right)^{1 / n}\right)$ & 153.40 & 156.53 & 168.34 \\
\multirow{3}{*}{ Temkin } & $R^{2}$ & 0.72 & 0.77 & 0.86 \\
& $R^{2}$ & 0.83 & 0.92 & 0.95
\end{tabular}

adsorbent. As shown in Table 6, the pseudo-second-order kinetic model has the highest $R^{2}$ value among the three models. Besides, the values of $q_{\mathrm{e}, \mathrm{cal}}$ that were calculated via the pseudo-second-order model exhibited a slight deviation from the experimental values $\left(q_{\mathrm{e}, \exp }\right)$. In other words, the pseudosecond-order model can be employed to describe the adsorption process. The results are also in agreement with other studies about the adsorption of MB by activated carbon based on durian shell and jackfruit pee ${ }^{25}$ and Siris seed pods. ${ }^{50}$ Fits of the pseudo-second-order model to the experimental data at 298 $\mathrm{K}$ at different initial concentrations are shown in Fig. 8A. The $k_{2}$ values of the pseudo-second-order model gradually decreased with an increase in the MB concentration. The cause of this phenomenon can be explained by the fact that competition for sorption surface sites increased with an increase in the MB concentration, which resulted in higher sorption rates.

The adsorption of $\mathrm{MB}$ onto the adsorbent is governed by either the liquid-phase mass transport rate or the intraparticle mass transport rate. ${ }^{49}$ The $R^{2}$ values (Table 6) for this model were lower in comparison to those obtained from the pseudosecond-order and pseudo-first-order models. In a plot of $q_{t}$ versus $t^{1 / 2}$ (Fig. 8B), the first, sharper portion represents instantaneous adsorption or adsorption on the external surface. The second portion corresponds to the stage of gradual adsorption where intraparticle diffusion is the rate-limiting process. In some cases a third portion exists, which represents the final equilibrium stage where intraparticle diffusion started to slow down owing to the extremely low adsorbate concentrations that remained in the solutions. As shown in Fig. 8B, the plot did not pass through the origin, and this deviation from the origin or near-saturation might be due to the difference in mass transfer rate in the initial and final stages of adsorption. From these results, it can be concluded that intraparticle diffusion is not the dominant mechanism in the adsorption of $\mathrm{MB}$ from aqueous solution. In other words, the results also prove that intraparticle diffusion is not the only rate-limiting step in the $\mathrm{MB}$ adsorption process.

\subsection{Adsorption thermodynamics studies}

The activation energy $E_{\mathrm{a}}\left(\mathrm{J} \mathrm{mol}^{-1}\right)$ for the adsorption of MB onto the adsorbent is calculated via the Arrhenius equation:

$$
\ln k_{2}=\ln A-\frac{E_{\mathrm{a}}}{R T}
$$

where $k_{2}\left(\mathrm{~g} \mathrm{mg}^{-1} \mathrm{~min}^{-1}\right)$ and $A$ are the average rate constant of the pseudo-second-order model and the Arrhenius factor, respectively. The $k_{2}$ values of the pseudo-second-order model at different temperatures and $\mathrm{MB}$ concentrations are shown in Table 7. The values of $E_{\mathrm{a}}$ and $A$ were calculated from a plot of ln $k_{2}$ vs. 1/T (Fig. 9A).

The value of $E_{\mathrm{a}}$ obtained for the adsorption of MB by the adsorbent is $13.48 \mathrm{~kJ} \mathrm{~mol}^{-1}$. In general, the activation energy ranges from 40 to $800 \mathrm{~kJ} \mathrm{~mol}^{-1}$ in chemical adsorption processes, whereas a value of $8-40 \mathrm{~kJ} \mathrm{~mol}^{-1}$ corresponds to a physical adsorption process. ${ }^{51}$ According to the calculated results, the adsorption of $\mathrm{MB}$ onto adsorbent-ultrasonic spray is a physical adsorption process. 
Table 5 Comparison of maximum monolayer adsorption capacity for MB of different adsorbents

\begin{tabular}{lll}
\hline Adsorbent & $\begin{array}{l}\text { Maximum monolayer } \\
\text { adsorption capacity }\left(\mathrm{mg} \mathrm{g}^{-1}\right)\end{array}$ & Reference \\
\hline Adsorbent-ultrasonic spray & 289.85 & This study \\
Rice husk & 129.5 & 44 \\
Pine wood powder & 200 & 45 \\
Apricot stone & 221.23 & 46 \\
Iron terephthalate (MOF-235) & 187 & 47 \\
$\mathrm{Fe}_{3} \mathrm{O}_{4} @$ GPTMS@Lys & 185 & 48
\end{tabular}
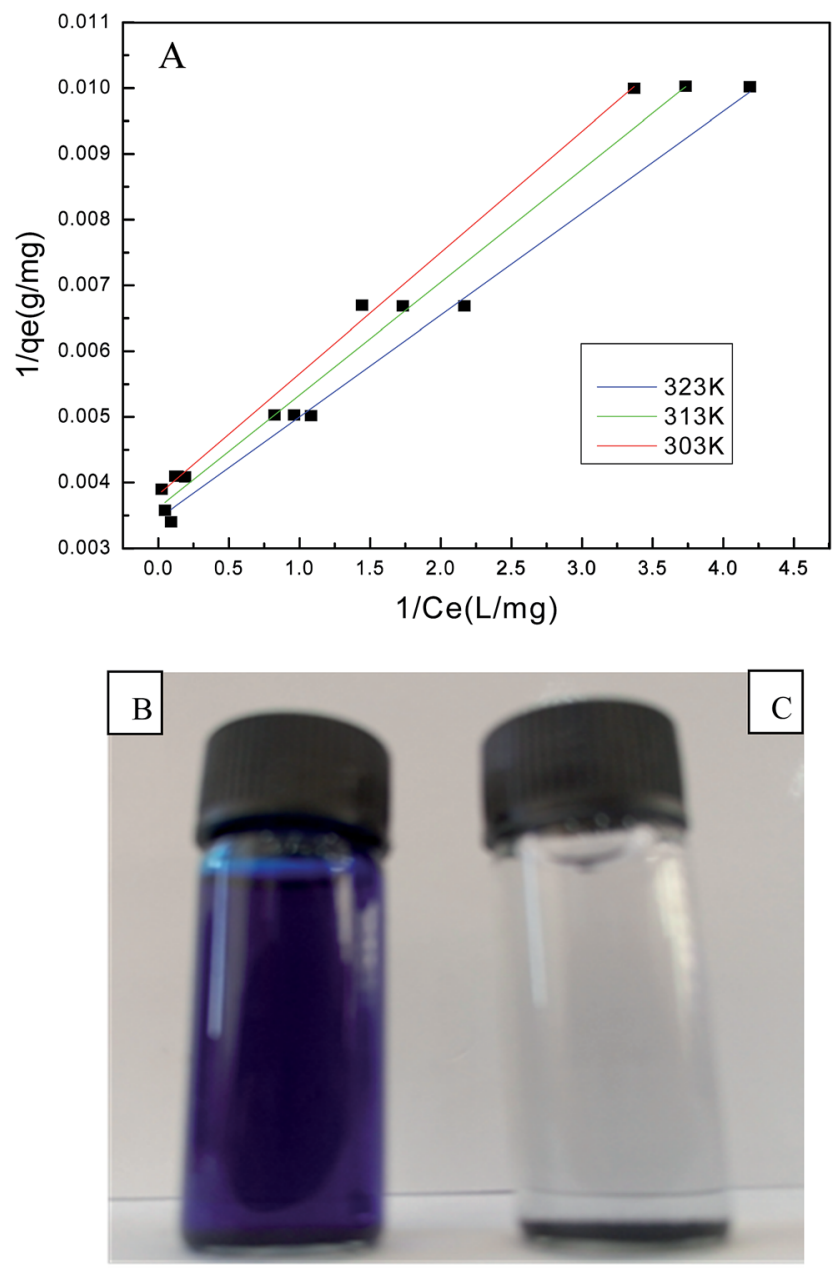

Fig. 7 (A) Langmuir isotherms for the adsorption of MB onto adsorbent-ultrasonic spray at different temperatures. ( $B$ and $C$ ) Photographs of $\mathrm{MB}$ solution (B) and the solution treated using adsorbent-ultrasonic spray (C).

The thermodynamic parameters, including the enthalpy $\Delta H$, free energy $\Delta G$ and entropy $\Delta S$ can be calculated from the following equations:

$$
\begin{aligned}
& \ln k_{\mathrm{d}}=\frac{\Delta S}{R}-\frac{\Delta H}{R T} \\
& \Delta G=-R T \ln \left(k_{\mathrm{d}}\right)
\end{aligned}
$$

\begin{tabular}{|c|c|c|c|c|c|}
\hline \multirow[b]{2}{*}{$C_{0}\left(\mathrm{mg} \mathrm{L}^{-1}\right)$} & \multicolumn{5}{|c|}{ Pseudo-first-order model } \\
\hline & $q_{\mathrm{e}, \exp }\left(\mathrm{mg} \mathrm{L}^{-1}\right)$ & \multicolumn{2}{|c|}{$q_{\mathrm{e}, \mathrm{cal}}\left(\mathrm{mg} \mathrm{L}^{-1}\right)$} & $k_{1}\left(\min ^{-1}\right)$ & $R^{2}$ \\
\hline 100 & 99.19 & 0.64 & & 0.0129 & 0.97 \\
\hline 150 & 149.14 & 3.84 & & 0.0174 & 0.86 \\
\hline 200 & 198.66 & 4.08 & & 0.0095 & 0.89 \\
\hline 250 & 243.39 & 15.96 & & 0.0102 & 0.83 \\
\hline \multirow[t]{2}{*}{300} & 252.88 & 26.58 & & 0.0112 & 0.93 \\
\hline & \multicolumn{5}{|c|}{ Pseudo-second-order model } \\
\hline$C_{0}\left(\mathrm{mg} \mathrm{L}^{-1}\right)$ & $q_{\mathrm{e}, \exp }\left(\mathrm{mg} \mathrm{L}^{-1}\right)$ & $q_{\mathrm{e}, \mathrm{cal}}\left(\mathrm{mg} \mathrm{L}^{-1}\right)$ & $k_{2}$ & $\left.\mathrm{mg}^{-1} \min ^{-1}\right)$ & $R^{2}$ \\
\hline 100 & 99.19 & 99.30 & 0.0 & & 1 \\
\hline 150 & 149.14 & 149.48 & 0.01 & & 1 \\
\hline 200 & 198.66 & 198.81 & 0.00 & & 0.99 \\
\hline 250 & 243.39 & 245.10 & 0.00 & & 0.99 \\
\hline \multirow[t]{2}{*}{300} & 252.88 & 255.75 & 0.0 & & 0.99 \\
\hline & \multicolumn{5}{|c|}{ Intraparticle diffusion model } \\
\hline$C_{0}\left(\mathrm{mg} \mathrm{L}^{-1}\right)$ & $q_{\mathrm{e}, \exp }\left(\mathrm{mg} \mathrm{L}^{-1}\right)$ & $C\left(\mathrm{mg} \mathrm{g}^{-1}\right)$ & $k_{3}(\mathrm{~m}$ & $\left.g g^{-1} \min ^{-1 / 2}\right)$ & $R^{2}$ \\
\hline 200 & 198.66 & 193.39 & 0.346 & & 0.80 \\
\hline 250 & 243.39 & 222.53 & 1.397 & & 0.80 \\
\hline 300 & 252.88 & 221.21 & 2.143 & & 0.84 \\
\hline
\end{tabular}

Table 6 Adsorption kinetics parameters at $298 \mathrm{~K}$

The values of $\Delta H$ and $\Delta S$ were calculated from the slope and intercept of eqn (9), respectively (Fig. 9B). The value of $\Delta G$ can be obtained from eqn (10) at 30-50 ${ }^{\circ} \mathrm{C}$. The values of $\Delta G$ at 30, 40 and $50{ }^{\circ} \mathrm{C}$ were $-10.11,-15.40$, and $-16.49 \mathrm{~kJ} \mathrm{~mol}^{-1}$, respectively. The negative values of $\Delta G$ suggest that the adsorption process was spontaneous. ${ }^{51}$ The values of $\Delta G$ decreased with an increase in temperature, which indicates that the adsorption of MB onto adsorbent-ultrasonic spray was easier at higher temperatures. The value of $\Delta H$ was $8.42 \mathrm{~kJ} \mathrm{~mol}^{-1}$, i.e. a positive value, which indicates that the adsorption process was endothermic. Previous research has reported that $\Delta H$ values for physical adsorption are less than $40 \mathrm{~kJ} \mathrm{~mol}^{-1} \cdot{ }^{52}$ Therefore, the adsorption process of $\mathrm{MB}$ can be classified as physical adsorption. The positive value of $\Delta S\left(76.13 \mathrm{~J} \mathrm{~mol}^{-1}\right)$ indicates an increase in randomness at the solid/solution interface during 
A

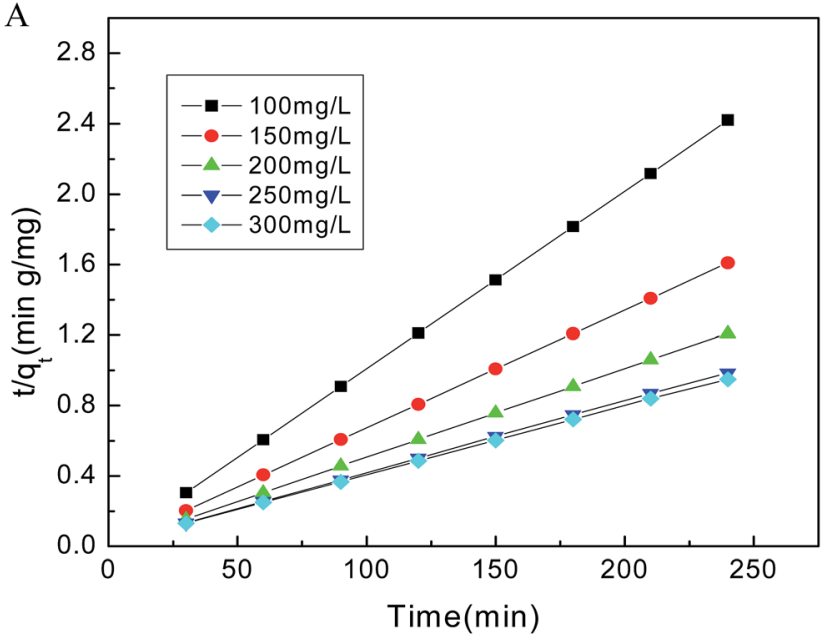

B

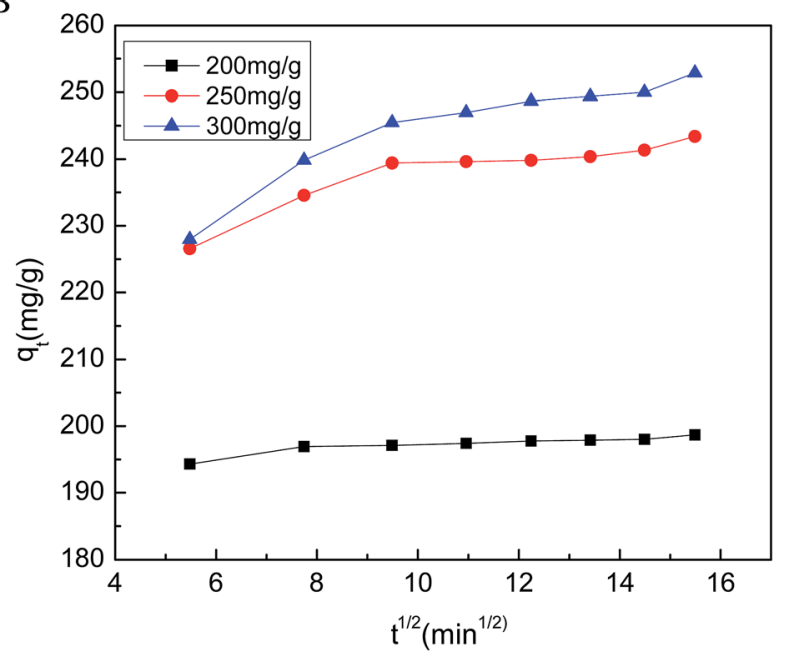

Fig. 8 (A) Pseudo-second-order kinetics for the adsorption of MB onto adsorbent-ultrasonic spray at $25^{\circ} \mathrm{C}$. (B) Intraparticle diffusion model for the adsorption of MB onto adsorbent-ultrasonic spray at $25^{\circ} \mathrm{C}$.

Table 7 Pseudo-second-order constants at different temperatures

$$
\underline{k_{2}\left(\mathrm{~g} \mathrm{mg}^{-1} \mathrm{~min}^{-1}\right)}
$$

\begin{tabular}{llll}
$\begin{array}{l}\text { Temperature } \\
\text { (K) }\end{array}$ & $\begin{array}{l}100 \mathrm{mg} \\
\mathrm{g}^{-1}\end{array}$ & $200 \mathrm{mg} \mathrm{g}^{-1}$ & $300 \mathrm{mg} \mathrm{g}^{-1}$ \\
\hline 303 & 0.0472 & 0.0062 & 0.001 \\
313 & 0.0443 & 0.0166 & 0.0007 \\
323 & 0.0557 & 0.0165 & 0.0009 \\
\hline
\end{tabular}

adsorption. These results also suggest that some structural changes occurred in the adsorbates and adsorbents. ${ }^{53}$

\subsection{Adsorption mechanism}

Fig. 10A shows the FTIR spectra of adsorbent-ultrasonic spray, $\mathrm{MB}$ and adsorbent-MB (after the adsorption of MB), which were recorded to investigate the adsorption mechanism. As was
A

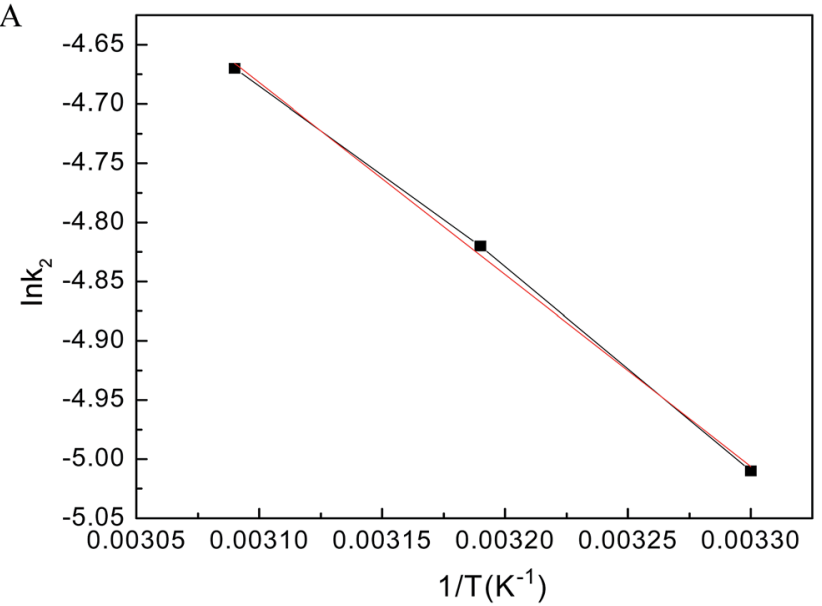

B

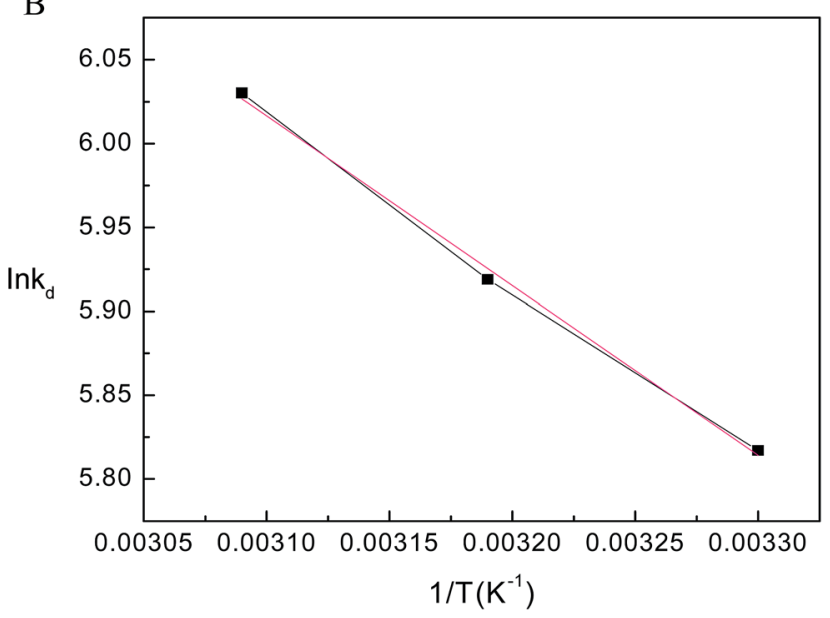

Fig. 9 (A) Arrhenius plot of $\ln k_{2}$ versus $1 / T$ for the adsorption of MB on adsorbent-ultrasonic spray. (B) Van't Hoff plot of $\ln k_{d}$ versus $1 / T$ for the adsorption of MB on adsorbent-ultrasonic spray.

discussed earlier, the characteristic peaks of adsorbentultrasonic spray in the band at $3431 \mathrm{~cm}^{-1}$ can be assigned to the $\mathrm{O}-\mathrm{H}$ stretching vibration mode of hydroxyl functional groups. The band at $1618 \mathrm{~cm}^{-1}$ is ascribed to $\mathrm{C}=\mathrm{O}$ groups, ${ }^{54}$ whereas the band at $1119 \mathrm{~cm}^{-1}$ represents $\mathrm{C}-\mathrm{OH}$ stretching vibrations of alcohol groups, phenolic aromatic rings and carboxylic groups. However, after the adsorption of MB onto adsorbent-ultrasonic spray, the FTIR spectrum of adsorbentultrasonic spray underwent changes. It is worth noting that the band at $1618 \mathrm{~cm}^{-1}$ shifted to $1616 \mathrm{~cm}^{-1}$ and the peak intensity was low, which suggests that $\mathrm{C}=\mathrm{O}$ bonds played a vital role in the adsorption process of MB. Fig. 10B shows the XPS core-level spectrum of adsorbent-ultrasonic spray after the adsorption of $\mathrm{MB}$. After adsorption, the content of $\mathrm{C}=\mathrm{O}$ groups in adsorbent-ultrasonic spray decreased from $16.19 \%$ to $8.39 \%$ and the content of $\mathrm{C}-\mathrm{O}$ groups hardly changed, which is in good agreement with the above analysis (compare Fig. 5B and 10B). As we known, $\mathrm{MB}$ is a cationic dye. The surface of AC-ultrasonic spray is negatively electrically charged owing to $\mathrm{C}=\mathrm{O}$ groups. A similar observation of the electrostatic attraction between some cationic dyes and magnetically modified multi-walled carbon 
A

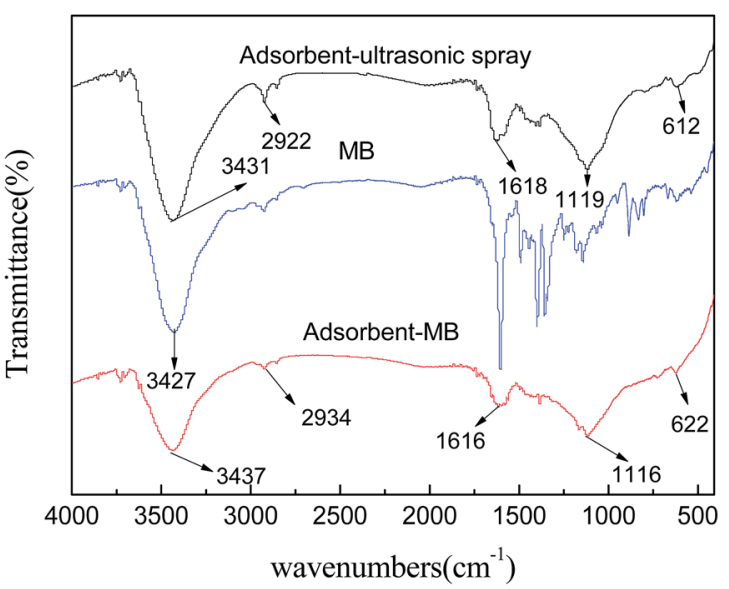

B

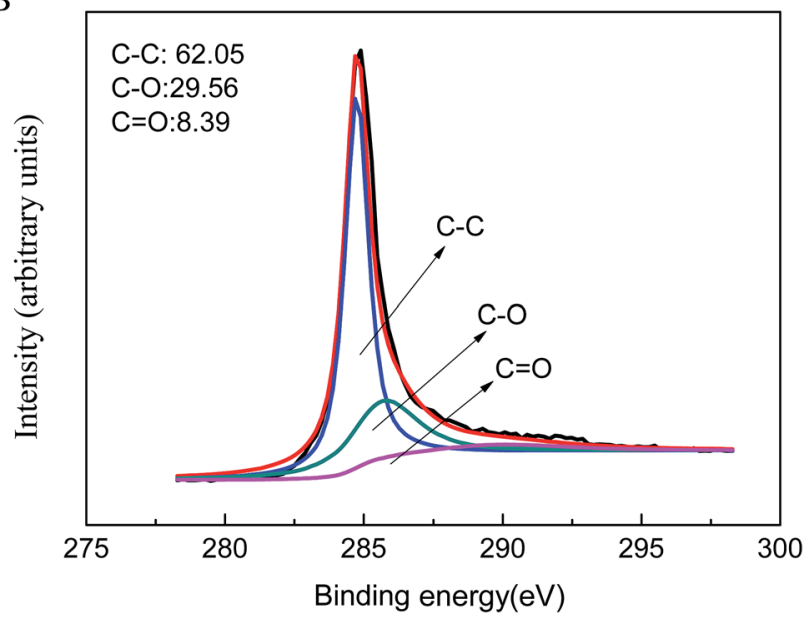

Fig. 10 (A) FTIR spectra of adsorbent-ultrasonic spray, MB and adsorbent-MB (after the adsorption of MB). (B) XPS core-level spectrum of adsorbent-ultrasonic spray after the adsorption of MB.

nanotubes has been reported by Madrakian et al. ${ }^{55}$ Hence, the electrostatic attraction between $\mathrm{MB}$ and adsorbent-ultrasonic spray contributed to the adsorption of MB. In addition, physical properties (surface area and pore structure) also contributed to the adsorption of $\mathrm{MB}$ as well as chemical properties (surface functional groups). The BET surface area and pore volume of adsorbent-ultrasonic spray are $1312 \mathrm{~m}^{2} \mathrm{~g}^{-1}$ and 1.34 $\mathrm{mL} \mathrm{g}^{-1}$, respectively, which make adsorbent-ultrasonic spray contact and adsorb MB efficiently. Electrostatic attraction and pore structure both contributed to the adsorption of $\mathrm{MB}$ onto adsorbent-ultrasonic spray.

\section{Conclusions}

Waste carbon obtained by decolorization in the production process of monosodium glutamate was used to prepare an adsorbent by microwave heating under an ultrasonic spray atmosphere. The adsorbent displayed a well-developed pore structure. An adsorbent was also prepared by steam treatment under the same conditions as were used for ultrasonic spray treatment. The exhaust gases that were obtained during the preparation process of the adsorbent had a certain heating value, as the major components were hydrogen and carbon monoxide. The exhaust gases have promising utility as a heat source, which would significantly alter the commercial manufacturing process and achieve the comprehensive utilization of waste resources.

Adsorption isotherms, adsorption kinetics, and adsorption thermodynamics were also studied. Analyses of the adsorption mechanism prove that $\mathrm{C}=\mathrm{O}$ bonds played an important role in the adsorption process of $\mathrm{MB}$. The equilibrium data were well described by the Langmuir model of adsorption for MB with a high adsorption capacity. The kinetic data were accurately represented by a pseudo-second-order kinetic model. Thermodynamics studies revealed that the adsorption process occurred spontaneously and was endothermic. The results of analyses show that the ultrasonic spray technique is an effective method for preparing adsorbents that display good performance in the removal of $\mathrm{MB}$.

\section{Acknowledgements}

The authors would like to express their gratitude to the Specialized Research Fund for the National Natural Science Foundation of China (51504119, 21567013), National High Technology Research and Development Plan (no. 2015AA020201, 863 Program), Yunnan Applied Basic Research Project (2015FB129), and the Yunnan Provincial Science and Technology Innovation Talents Scheme Technological Leading Talent (2013HA002).

\section{References}

1 S. Nethaji and A. Sivasamy, Chemosphere, 2011, 82, 13671372.

2 M. Ghaedi, A. G. Nasab, S. Khodadoust, R. Sahraei and A. Daneshfar, J. Ind. Eng. Chem., 2015, 21, 986-993.

3 A. Mirzaei, A. Ebadi and P. Khajavi, Chem. Eng. J., 2013, 231, 550-560.

4 M. Ghaedi, M. Ghayedi, S. N. Kokhdan, R. Sahraei and A. Daneshfar, J. Ind. Eng. Chem., 2013, 19, 1209-1217.

5 B. Kayan, B. Gözmen, M. Demirel and A. M. Gizir, J. Hazard. Mater., 2010, 177, 95-102.

6 F. Esther, C. Tibor and O. Gyula, Environ. Int., 2004, 30, 953971.

7 A. R. Tehrani-Bagha, N. M. Mahmoodi and F. M. Menger, Desalination, 2010, 260(1-3), 34-38.

8 E. A. DeLara, S. B. Damas, M. I. A. Miranda and M. I. I. Clar, J. Hazard. Mater., 2012, 209-210, 492-500.

9 R. Tim, M. M. Geoff, M. Roger and N. Poonam, Bioresour. Technol., 2001, 77, 247-255.

10 G. Mehrorang, H. Shaaker, B. Behnaz, K. Farahnaz and G. Gholamreza, J. Ind. Eng. Chem., 2013, 19, 227-233.

11 T. Jiang, Y. D. Liang, Y. J. He and W. Qing, J. Environ. Chem. Eng., 2015, 3, 1740-1751.

12 T. A. Saleh and V. K. Gupta, Adv. Colloid Interface Sci., 2014, 211, 93-101. 
13 N. Yoshizawa, Y. Yamada, T. Furuta, M. Shiraishi, S. Kojima, H. Tamai and H. Yasuda, Energy Fuels, 1997, 11, 327-330.

14 T. Siemieniewska, A. Albiniak, E. Broniek, J. Kaczmarczyk, A. Jankowska, B. McEnaney, X. S. Chen, E. Alain, G. Furdin and D. Begin, Fuel, 1998, 77, 509-517.

15 Y. Q. Guo and E. Du, Energy Procedia, 2012, 17, 444-449.

16 W. H. He, G. C. Lu, J. Cui, L. M. Wu and L. B. Liao, Chin. J. Chem. Eng., 2012, 20, 659-666.

17 A. Özgür and C. Ferhan, Int. Biodeterior. Biodegrad., 2007, 59(4), 257-272.

18 K. Behroz, H. E. Mohammad and E. Asghar, Iran. J. Environ. Health Sci. Eng., 2013, 10(1), 1-7.

19 C. H. Weng and M. C. Hsu, Sep. Purif. Technol., 2008, 64, 227236.

20 J. L. Lim and M. Okada, Ultrason. Sonochem., 2005, 12(4), 277-282.

21 K. Y. Foo and B. H. Hameed, J. Anal. Appl. Pyrolysis, 2012, 98, 123-128.

22 X. H. Duan, C. Srinivasakannand and W. W. Qua, Chem. Eng. Process., 2012, 53, 53-62.

23 J. W. Zondlo and M. R. Velez, Fuel Process. Technol., 2007, 88(4), 369-374.

24 H. Y. Xia, J. Wu, Y. Xia, L. B. Zhang and J. H. Peng, J. Porous Mater., 2015, 22, 137-146.

25 K. Y. Foo and B. H. Hameed, Chem. Eng. J., 2012, 193-194, 404-409.

26 S. C. Ma, X. Y. Ma, T. X. Guo and Y. Zhao, J. Fuel Chem. Technol., 2010, 38(6), 739-744.

27 C. H. Lim and K. T. Lee, Ceram. Int., 2016, 42, 13715-13722.

28 J. V. Kumar, A. Maldonado and M. Olvera, Mater. Lett., 2015, 157, 169-171.

29 K. G. Deepa, C. Gauthaman and J. Nagaraju, J. Anal. Appl. Pyrolysis, 2016, 120, 356-360.

30 Y. Gao, Q. Y. Yue, B. Y. Gao, Y. Y. Sun, W. Y. Wang, Q. Li and Y. Wang, Chem. Eng. J., 2013, 217, 345-353.

31 B. Ledesma, S. Román, A. Álvarez-Murillo, E. Sabio and J. F. González, J. Anal. Appl. Pyrolysis, 2014, 106, 112-117.

32 J. K. Jeon, H. Kim, Y. K. Park, C. H. F. Peden and D. H. Kim, Chem. Eng. J., 2011, 174, 242-248.

33 S. Kasaoka, Y. Sakata, E. Tanaka and R. Naitoh, Int. Chem. Eng., 1989, 29, 734-742.

34 S. Cheng, L. B. Zhang, H. Y. Xia, J. H. Peng, S. Z. Zhang and S. X. Wang, J. Porous Mater., 2015, 20, 1527-1537.
35 Q. S. Liu, T. Zheng, N. Li, P. Wang and G. Abulikemu, Appl. Surf. Sci., 2010, 256, 3309-3315.

36 H. Deng, G. X. Li, H. B. Yang, J. P. Tang and J. Y. Tang, Chem. Eng. J., 2010, 163, 373-381.

37 Y. H. Huang, M. Erni and G. J. Zhao, Ind. Crops Prod., 2015, 69, 447-455.

38 S. F. Adriana, S. O. Leandro, A. A. Nunes and C. O. A. Cibele, Bioresour. Technol., 2010, 101, 1068-1074.

39 S. Karthikeyan, R. Boopathy and G. Sekaran, J. Colloid Interface Sci., 2015, 448, 163-174.

40 Y. H. Li, Q. J. Du, X. D. Wang, P. Zhang, D. C. Wang, Z. H. Wang and Y. Z. Xia, J. Hazard. Mater., 2010, 183, 583589.

41 X. Song, H. Liu, L. Cheng and Y. Qu, Desalination, 2010, 255, 78-83.

42 Y. H. Li, S. Wang, A. Cao, D. Zhao, X. Zhang, C. Xu, Z. Luan, D. Ruan, J. Liang, D. Wu and B. Wei, Chem. Phys. Lett., 2001, 350, 412-416.

43 K. S. Theydan and M. J. Ahmed, J. Anal. Appl. Pyrolysis, 2012, 97, 116-122.

44 P. Gao, Z. H. Liu, G. Xue, B. Han and M. H. Zhou, Bioresour. Technol., 2011, 102, 3645-3648.

45 T. H. Wang, S. X. Tan and C. H. Liang, Carbon, 2009, 47, 1867-1885.

46 E. Demirbas, M. Kobya and M. T. Sulak, Bioresour. Technol., 2008, 99, 5368-5373.

47 E. Haque, J. W. Jun and S. H. Jhung, J. Hazard. Mater., 2011, 185, 507-511.

48 Y. R. Zhang, S. L. Shen, S. Q. Wang, J. Huang, P. Su, Q. R. Wang and B. X. Zhao, Chem. Eng. J., 2014, 239, 250-256.

49 K. Y. Foo and B. H. Hameed, Chem. Eng. J., 2011, 173, 385390.

50 J. A. Muthanna and K. T. Samar, J. Anal. Appl. Pyrolysis, 2013, 99, 101-109.

51 M. Auta and B. H. Hameed, Chem. Eng. J., 2014, 237, 350361.

52 Y. J. Yao, F. F. Xu, M. Chen, Z. X. Xu and Z. W. Zhu, Bioresour. Technol., 2010, 101, 3040-3046.

53 K. Y. Foo and B. H. Hameed, Chem. Eng. J., 2012, 184, 57-65.

54 V. O. Njoku, K. Y. Foo and B. H. Hameed, Chem. Eng. J., 2013, 215-216, 383-388.

55 T. Madrakian, A. Afkhami, M. Ahmadi and H. Bagheri, J. Hazard. Mater., 2011, 196, 109-114. 